Geografia e Ordenamento do Território, Revista Electrónica

Centro de Estudos de Geografia e Ordenamento do Território

http://cegot.org

ISSN : 2182-1267

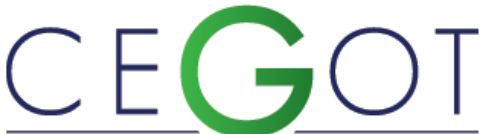

Centro de Estudos de Geografia e Ordenamento do Território
Guardamagna,MeLina

Universidad Nacional de Cuyo. Facultad de Ciencias Políticas y Sociales. Centro de Estudios de Innovación Institucional (CEII). CONICET 5501. Lainez 68. Godoy Cruz. Mendoza. Argentina meliguardamagna@gmail.com

\title{
El ordenamiento del territorio en Mendoza, Argentina: la implementación ¿participativa? de una política
}

\author{
O ordenamento territorial em Mendoza, Argentina. A implementação \\ participativa de uma política? \\ Territorial planning and land use in Mendoza, Argentina: the participatory \\ implementation of a policy?
}

Referência: Guardamagna, Melina (2016). El ordenamiento del territorio en Mendoza, Argentina: la implementación ¿participativa? de una política. Revista de Geografia e Ordenamento do Território (GOT), n.으 10 (dezembro). Centro de Estudos de Geografia e Ordenamento do Território, p. 159-187, dx.doi.org/10.17127/got/2016.10.008

\section{RESUMEN}

En los últimos años, en Argentina y en particular en la provincia de Mendoza se ha avanzado en la formulación e implementación de una política de ordenamiento territorial y usos del suelo como un instrumento de planificación que busca contribuir al desarrollo territorial.

Este estudio constituye un análisis crítico de dicha política y, principalmente, de su etapa de implementación definida desde una concepción sistémica del territorio y cuya principal característica intenta ser la participación de la ciudadanía.

Palabras claves: ordenamiento; territorio; implementación; política pública; participación ciudadana

\section{RESUMO}

Nos últimos anos, na Argentina e particularmente na província de Mendoza, tem-se avançado na formulação e implementação de uma política de ordenamento do território e 
dos usos do solo como um instrumento de planificação que tenta contribuir para o desenvolvimento regional. Este estudo constitui uma análise crítica dessa política e principalmente da sua fase de implementação definida a partir de uma visão sistémica do território e cuja principal característica pretende ser a participação dos cidadãos.

Palavras-chave: ordenamento; território; implementação; política pública; participação cidadã.

\section{ABSTRACT}

There has been an important progress on the formulation and implementation of a land use policy that could be used as a planning instrument to contribute to the territorial development in Argentina, particularly in the Mendoza region, during recent years.

This research constitutes a critical analysis of those policies, especially of the implementation stage. That first step has been defined following a systemic conception of the territory, whose main feature is intended to be the citizen participation.

Keywords: land use; territory; implementation; public policy; citizen participation

\section{Introducción}

La provincia de Mendoza, perteneciente a la Región de Cuyo y ubicada al noroeste del territorio argentino, presenta características particulares vinculadas a los oasis irrigados que "ocupan apenas el 3\% de su superficie y en ellos se concentra más del 90\% de la actividad económica y el asentamiento del 65\% de la población provincial" (DGI, 2005).

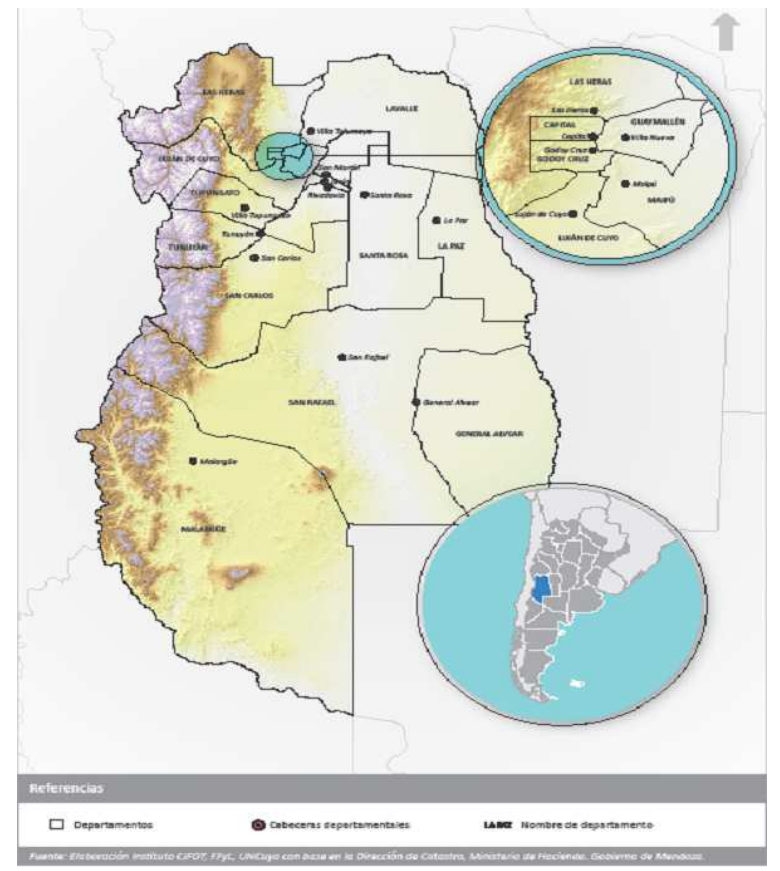

Figura 1 - Mapa físico-político de la província de Mendoza Fuente: Elaboración Instituto CIFOT, FFyt 
Sumado a lo cual, para 2020 se proyecta un crecimiento del 15\% en la población (DEIE, 2010), lo que incrementará las demandas y conflictos en torno a los escasos recursos disponibles. Esta es, sin duda, una de las razones por las cuales la problemática del ordenamiento del territorio y los usos del suelo forma parte de la agenda provincial desde hace más de diez años.

Este trabajo pone el acento en el proceso de implementación de la política de Ordenamiento Territorial y Usos del Suelo, y específicamente del Plan Provincial de Ordenamiento Territorial -PPOT-, etapa central en el ciclo de la misma. A los fines analíticos de la presente investigación ubicamos el inicio de dicho proceso en Mendoza en el año 2009 a partir de la sanción de la Ley № 8051.

La Ley de Ordenamiento Territorial y Usos del Suelo $N^{\circ} 8.051$ establece, desde una concepción sistémica del territorio, procedimientos para la elaboración del Plan de Ordenamiento Territorial provincial y de los municipios. Para ello, define una implementación, en diversas etapas, a partir de un tipo de planificación normativa que incorpora un proceso de construcción colectivo, garantizando la participación ciudadana.

En un artículo anterior (Guardamagna, Cueto, 2015), bajo el supuesto de que la falta de cohesión sistémica podría dificultar e incluso imposibilitar la construcción de un Modelo Territorial Deseado a partir del cual se desarrolle el plan provincial y los planes municipales, examinamos, a partir de una metodología de tipo cualitativa que nos permitió, a través de una estudio exploratorio, la construcción de una matriz normativa ${ }^{1}$, la correspondencia teórico-metodológica entre las diversas etapas que la ley precisa y el desarrollo efectivo del proceso de planificación, refiriéndonos específicamente a la elaboración del diagnóstico; el modelo territorial; los escenarios alternativos y la identificación de acciones prioritarias para la provincia.

Entre las conclusiones a las que arribamos en dicho análisis, algunas de las más significativas indican que: más allá de que las etapas previstas por la ley se cumplieron, en el proceso entre la elaboración del diagnóstico y la identificación del plan de acciones se produjeron tensiones, conflictos y cambios entre los actores responsables del diseño. Asimismo se generaron inconsistencias teórico-metodológicas entre las prescripciones legales y las propuestas efectivas e inclusive modificaciones en los criterios para definir el formato final del llamado "Documento Preliminar" (2014).

\footnotetext{
${ }^{1}$ En el marco del proyecto de investigación № 06/F334 "La implementación de una política pública en contexto de complejidad normativa: el caso del ordenamiento territorial en Mendoza a partir de 2009". Secretaría de Ciencia, Técnica y Postgrado. UNCuyo. Programa de Incentivos 2013/2015 se han elaborado y publicado diversos artículos que expresan resultados preliminares de la investigación. Los mismos responden a los objetivos, hipótesis y metodología del proyecto de investigación.
} 
Dentro de las inconsistencias teórico-metodológicas encontradas, tal vez las que mayores consecuencias tendrán en la implementación de las etapas posteriores tienen que ver la utilización de distintas unidades de análisis para la elaboración de los diagnósticos por subsistema. Sumado a lo cual tampoco se definió una metodología para la interrelación de los mismos, por lo que el modelo deseado se terminó construyendo a partir de los procesos críticos identificados en el diagnóstico del Plan Estratégico de Desarrollo Mendoza 2030 PEDMza 2030- sin incorporar los diagnósticos situacionales desarrollados para cada subsistema. Además la delimitación de los mecanismos de participación ciudadana fue débil e imprecisa, poniendo en cuestionamiento el efectivo involucramiento de la sociedad en el proceso.

Por otro lado, la forma asistemática y con un altísimo nivel de generalidad y abstracción con la que se presentó el plan de acción difícilmente sirva como insumo para la elaboración del PPOT.

En el presente trabajo vamos a continuar realizando un contraste entre la prescripción normativa y las actividades efectivas que los actores concretaron para diseñar el proceso de implementación del PPOT pero poniendo ahora especial atención en la etapa posterior a la culminación del Documento Preliminar del Plan Provincial. Es decir que nuestro estudio atenderá el período que va desde la presentación del mismo al Consejo Provincial de Ordenamiento Territorial -CPOT-, pasando por las instancias de validación ciudadana Consulta Pública y Audiencia Pública- hasta su remisión a la Legislatura provincial, donde actualmente se encuentra.

Para ello, el artículo se ha estructurado en cuatro partes. La primera donde se explicita la secuencia de planificación definida por la ley, distinguiendo fundamentalmente procedimientos, acciones y sujetos responsables de la elaboración del PPOT. La segunda donde analizamos el lugar de la participación ciudadana en el proceso. La tercera referida a la elaboración del proyecto que finalmente ingresó a la Legislatura. Y la cuarta donde analizamos en forma comparada esta versión del PPOT y la de un grupo de especialistas del sector científico presentada al Senado con posterioridad.

\section{La secuencia en el proceso de planificación}

Los capítulos de la Ley 8051/09 que hacen referencia a los procedimientos para la elaboración y aprobación del plan provincial son, principalmente, el 2 y 3.

En el capítulo II, sobre los Instrumentos del Ordenamiento Territorial el artículo 10 define la jerarquía de los conceptos que se utilizarán en el resto de la norma y luego, al momento de 
la elaboración de los planes. Para ello establece la siguiente estructura con sus respectivas definiciones:

a) "Planes de Ordenamientos Territoriales: estos comprenden el Plan Provincial de Ordenamiento Territorial y los Planes Municipales de Ordenamiento Territorial, el Plan de Ordenamiento Territorial Metropolitano para el Gran Mendoza, los Planes de Ordenamiento Territorial de Áreas Especiales y los Planes Sectoriales o Intersectoriales. Contienen estrategias que orientan su ejecución y objetivos para alcanzar el modelo territorial deseado.

b) Programas: se trata de instrumentos rectores, derivados de la planificación institucional, conformados por un conjunto de proyectos formulados para alcanzar determinados objetivos, establecidos en los Planes de Ordenamiento Territorial.

c) Proyectos: conjunto de obras o actividades destinadas a alcanzar el cumplimiento de objetivos y metas definidos por un programa, tendientes a la obtención de resultados concretos de acuerdo al ámbito de competencia y responsabilidad de cada unidad, que pueden, planificarse, analizarse y ejecutarse administrativamente en forma específica" (art. 10. Ley 8051/09).

El artículo 13, determina que los planes "serán las herramientas territoriales que darán lugar a la generación de medidas correctivas, de conservación y de desarrollo territorial, haciendo uso de programas y proyectos de gestión, que garanticen la interacción entre las distintas instituciones y los mecanismos de participación social" (art. 13. Ley 8051/09).

A lo largo de estos capítulos y sus artículos se evidencia una necesidad excesiva de normatizar hasta lo que se entenderá por cada uno de los conceptos que utiliza la política, lo que, como veremos más adelante, no garantiza que no se genere una brecha entre el diseño y la etapa de implementación.

A continuación la ley define una secuencia en el proceso de planificación en etapas, es decir, procedimientos específicos para la elaboración de los planes.

\begin{tabular}{|l|l|}
\hline \multirow{4}{*}{ “Etapas esenciales del plan" } & 1. DIAGNÓSTICO \\
\cline { 2 - 3 } & 2. MODELO TERRITORIAL \\
\cline { 2 - 3 } & 3. ESCENARIOS ALTERNATIVOS \\
\cline { 2 - 3 } & 4. IDENTIFICACIÓN DE ACCIONES \\
\cline { 2 - 3 } & 5. PROYECTO DE PLAN O PROGRAMA \\
\hline & 6. INFORMES SECTORIALES \\
\hline & 7. EVALUACIÓN AMBIENTAL ESTRATÉGICA \\
\hline & 8. INFORMACIÓN Y PARTICIPACIÓN PÚBLICA \\
\cline { 2 - 2 } & 9. APROBACIÓN DEL PLAN O PROGRAMA \\
\hline
\end{tabular}

Cuadro $\mathrm{N}^{\circ}$ 1: Etapas para la elaboración de los Planes

Fuente: Elaboración propia a partir del art. 16 de la Ley N 8051/09.

En este trabajo nos centraremos en las etapas que van desde la elaboración del proyecto de plan o programa hasta su presentación en la Legislatura para su aprobación, pasando por las 
instancias de participación pública. Sin embargo, lo que se evidencia en el proceso de implementación de la política, tal como lo analizaremos más adelante, es que se fueron salteando etapas de la secuencia definida por la norma y, tal vez lo más preocupante, algunas de las que efectivamente se cumplieron, sólo fue en los términos formales, pero no en los sustanciales.

Los artículos 17, 18 y 19 de carácter procedimental, establecen las normas de aprobación -el plan de ordenamiento territorial por ley y los planes municipales por ordenanza municipal (art. 17. Ley 8051/09)-; los plazos de elaboración de los planes -6 meses desde la promulgación de la ley para la elaboración del Plan Estratégico de Desarrollo de Mendoza, 18 meses desde la remisión de este a la Legislatura para la confección del Plan Provincial de Ordenamiento Territorial y 12 meses desde la aprobación del Plan para que cada Municipio realice su plan (art. 18. Ley 8051/09)- y las sanciones por su incumplimiento.

En los hechos, los plazos se alejaron de lo dispuesto por la norma, lo que daría lugar a sanciones administrativas y penales sobre los funcionarios implicados (art. 19. Ley 8051/09). La ley se publicó en el Boletín Oficial en el mes de mayo de 2009. Un año y siete meses después, en diciembre del 2010, se sancionó el PED Mza2030 y recién luego de 3 años y cuatro meses, en abril de 2014, el Ejecutivo envió el proyecto del PPOT a la Legislatura, donde se encuentra parado desde entonces.

El capítulo 3 hace referencia específicamente a todo lo vinculado a la elaboración del PPOT. En dicho sentido identifica a los principales actores de la política, estos son el Poder Ejecutivo a través de la Autoridad de Aplicación ${ }^{2}$ responsable de la elaboración del plan, la Legislatura de quien dependerá su aprobación y las reparticiones y organismos competentes a cargo de la implementación (art. 20. Ley 8051/09).

Mientras que el artículo 21 define los contenidos básicos que deberá tener en tanto "marco de referencia sistémico y específico para la formulación y gestión de las acciones públicas y privadas" que impactan sobre el territorio provincial. Se trata de un extenso artículo donde se enumeran un conjunto de acciones, algunas de carácter instrumental y otras de contenidos -definidos e indefinidos-, que a los fines del proceso de implementación de la política que estamos analizando hemos tratado de ordenar siguiendo la secuencia lógica de la norma que va desde la definición de directrices hasta la enunciación de un conjunto de acciones a las que el plan tendría que responder; veremos luego si esto ocurrió o no.

\footnotetext{
${ }^{2}$ De acuerdo al artículo 39 de la Ley 8051/09, "la Autoridad de Aplicación será la Secretaría de Medio Ambiente o el organismo que en el futuro la reemplace y los Municipios serán Autoridad de Aplicación de esta ley en sus respectivas jurisdicciones...". Asimismo, se crea para el cumplimiento de esta tarea, el Consejo Provincial de Ordenamiento Territorial (CPOT) y la Agencia Provincial de Ordenamiento Territorial (APOT). La Agencia es un órgano desconcentrado del Poder Ejecutivo. Entre sus principales funciones se encuentra la de "elaborar los proyectos de los planes de Ordenamiento Territorial" (art. 41. Ley 8051/09).
} 


\section{CAPITULO 3: Elaboración del Plan de Ordenamiento Territorial}

\section{Acción y contenido por inciso:}

\section{(a)}

Crear y establecer las grandes directrices territoriales (Definida de contenido) (b)

Determinar las prioridades de la acción publica y privada a escala provincia Definida de conce

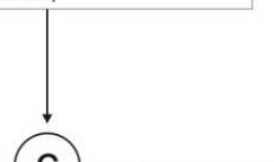

$$
\text { (C) }
$$

Definir e inventariar las caracteristicas ambientales, geomorfológicos, geológicas, hidrológicas y topográficas en relación con los presupuestos minimos de riesgos los presupuestos minimos de riesgos
naturales (Definida de contenido)

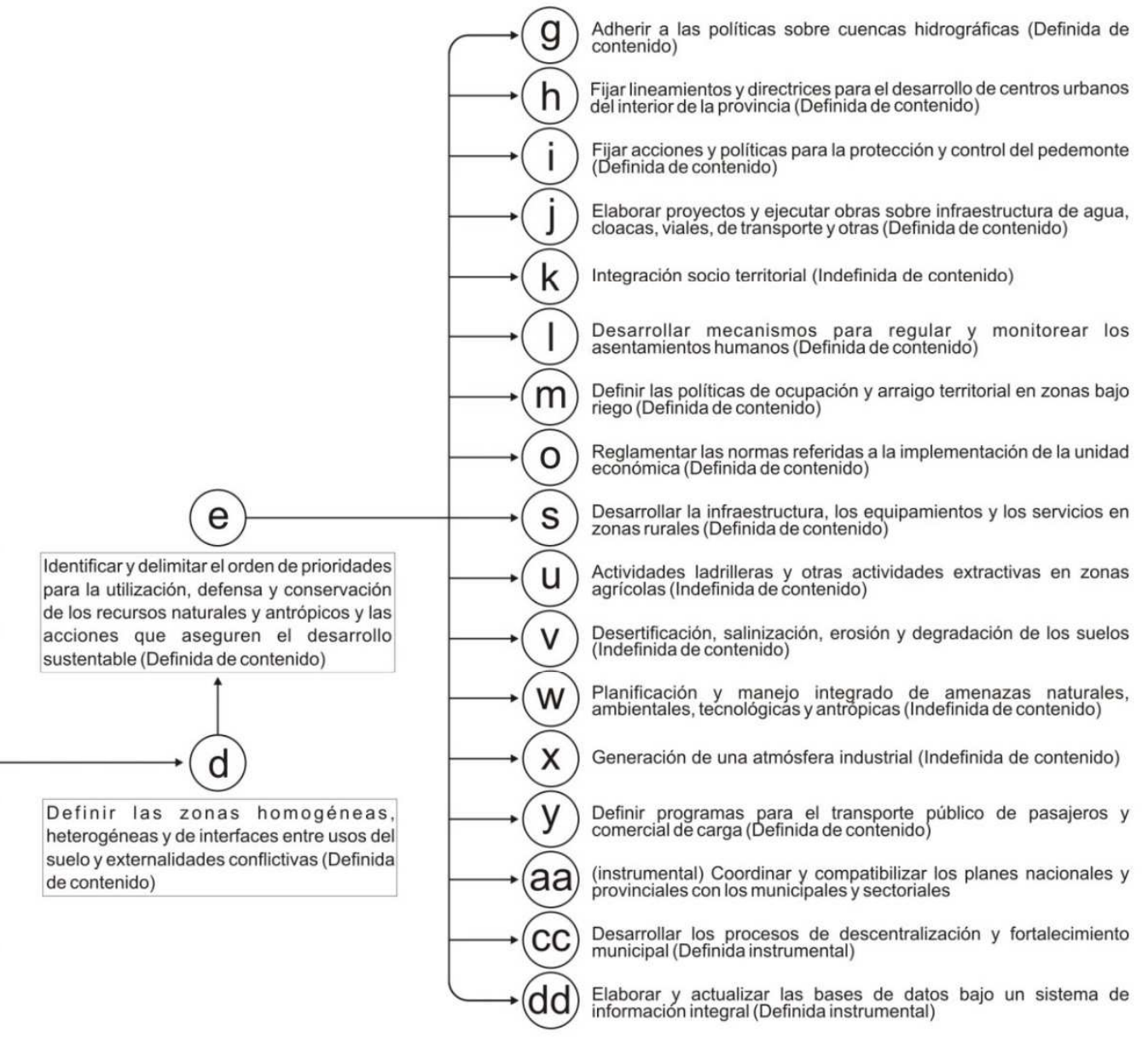

Cuadro n.․ 2

Fuente: Elaboración propia a partir del art. 21, capítulo 3. Ley № 8051/09. 
A partir del análisis de estos artículos, podemos decir que la ley precisa una secuencia de implementación para el proceso de planificación en la que se detalla un conjunto de instrumentos y una secuencia de etapas. Para la confección del PPOT establece además un extenso y preciso conjunto de acciones, lo que a priori podría aparecer como de un excesivo normativismo que podría propiciar el cumplimiento de las formas legales, dejando de lado el contenido sustancial, que en definitiva es lo que quienes redactaron las norma querían resguardar.

Ahora bien ¿Cuáles fueron y cómo se instrumentaron las instancias de participación ciudadana previstas por la ley en dicho proceso? ¿Cuál fue el proceso de implementación de la política hasta llegar a la presentación del Plan Provincial de OT para su tratamiento y aprobación en la Legislatura provincial? ¿Cuáles fueron las disidencias entre el Poder Ejecutivo y el sector técnico-científico?

\section{El lugar de la participación ciudadana en el proceso de planificación de la política}

La participación ciudadana constituye un requisito central en la formulación de políticas públicas en democracia. Más aún en temas que afectan en forma directa y, por lo tanto, a una escala local, la vida de los ciudadanos. La participación de la sociedad atraviesa, en este sentido, todas las etapas de la política de Ordenamiento Territorial ${ }^{1}$, lo que también supone desafíos y dificultades al momento de su implementación. Tal como afirma Manero "el concepto de participación ciudadana ocupa en nuestros días una posición muy destacada en el debate sobre el modo de entender y ejecutar las políticas públicas tanto por el margen de posibilidades que se le reconoce en el sistema regulador como por las incertidumbres, contradicciones y conflictos que genera. Identificado asimismo como uno de los pilares en los que se fundamentan los enfoques aplicados a la gobernanza y a la ordenación integrada y sostenible del territorio" (2010:47).

Los modos de implementación, en el ámbito del ordenamiento del territorio, varían de una legislación a otra de acuerdo a los objetivos y resultados que se pretenden alcanzar. Para

\footnotetext{
${ }^{1}$ Las etapas previas del proceso de implementación, definidas por la Ley 8051/09, -diagnóstico; modelos territoriales; escenarios alternativos; identificación de acciones- junto a las instancias de participación ciudadana desarrolladas en cada una de ellas, son analizadas en un trabajo anterior (Guardamagna, Melina y Cueto, Walter. La implementación de la Política de Ordenamiento Territorial en Mendoza, Argentina: una mirada crítica sobre diseño del Plan Provincial. Revista Enfoques. 2015. 13(22). Santiago de Chile. [Abril, 2016]. Disponible en: dehttp://www.revistaenfoques.cl/index.php/revista-uno/article/view/335
} 
Arteaga "la participación ciudadana puede darse en diferentes formas: en el nivel de consulta la población no sólo conoce propuestas y decisiones, sino que expresa su parecer sobre un determinado evento y declara, en función de sus intereses, un conjunto de necesidades, aspiraciones y puntos de vista" (2003: 73 en Martínez y otros, 2005: 195).

Nos encontramos entonces ante un gran desafío al reconocer a la participación ciudadana como una de los baluartes esenciales de las políticas orientadas a la ordenación del territorio (Manero, 2010: 52). Esto tiene que ver con el interrogante de cómo superar la contradicción entre la implicación de la sociedad en estos procesos de planificación y la calidad de los mecanismos de gestión pública para que la misma sea realmente efectiva y no, solamente, el cumplimiento formal de la norma que la legisla.

\section{1. ¿Qué dice la ley y cómo regula la participación de la ciudadanía en el proceso de planificación?}

Tal como decíamos anteriormente, cada una de las etapas definidas por la ley prevé el involucramiento de la sociedad. De hecho, uno de los criterios que la norma precisa para la elaboración de los planes es la participación social: "Ios Planes de Ordenamiento Territorial deberán permitir la intervención de todos los actores involucrados a fin de priorizar metas y objetivos, detectar problemas y conflictos y establecer las acciones a seguir, logrando el máximo nivel de beneficio público posible, definiendo propósitos, objetivos y metas compartidas, que permitan alcanzar los objetivos fijados por los planes" (Inc. I. Anexo 2. Art. 11. Cap. 2. Ley № 8051/09).

Además, el capítulo 8 referido específicamente a la participación ciudadana define los mecanismos para garantizar la información y la participación social. En dicho sentido, como parte de las etapas que estamos analizando en este trabajo (ver Cuadro № 1) la ley establece dos procedimientos específicos: la consulta pública y las audiencias públicas.

El objeto de la Consulta Pública es "garantizar la participación y el derecho a la información mediante un procedimiento que contribuya a la toma de decisiones por parte de la autoridad de aplicación" (art. 44. Ley № 8051/09).

En el caso de las audiencias públicas podrán convocarse "con un plazo mínimo de diez (10) días hábiles posteriores a la finalización de la Consulta Pública y en forma previa a resolver sobre temas que, por su significación y evaluación, tengan trascendencia permanente y general para la población de la Provincia..." (art. 48. Ley № 8051/09). 


\section{2. ¿Cómo y en qué contexto se instrumentaron los procedimientos de participación ciudadana?}

En cumplimiento de las etapas dispuestas por la Ley 8051/09, la Consulta Pública fue convocada por el Ministerio de Tierras, Ambiente y Recursos Naturales entre los días 10 y 21 de febrero de 2014.

Al mismo tiempo, el CPOT dividido en tres comisiones: Comisión de Instrumentos del Plan; Comisión de Procedimiento de Elaboración del Plan y Comisión de Contenido del Plan trató el documento preliminar, a fin de revisarlo y mejorarlo, en las sesiones del 5 de febrero; 19, 20, 25 y 26 de marzo y 24 de abril de 2014.

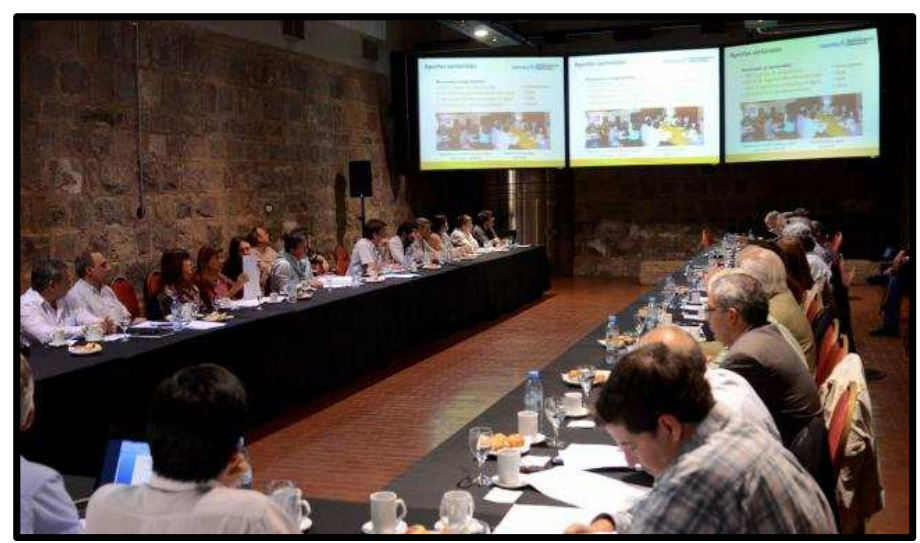

Figura 2

Referencia: Sesión del Consejo Provincial de Ordenamiento Territorial. Abril, 2014.

La Audiencia por su parte, fue convocada para el día 15 de Abril de 2014. Fijándose además varias instancias de inscripción previa para los interesados en participar. Más de 500 personas realizaron el trámite, aunque finalmente sólo 130 tomaron la palabra (Diarios Los Andes, 16/04/14).
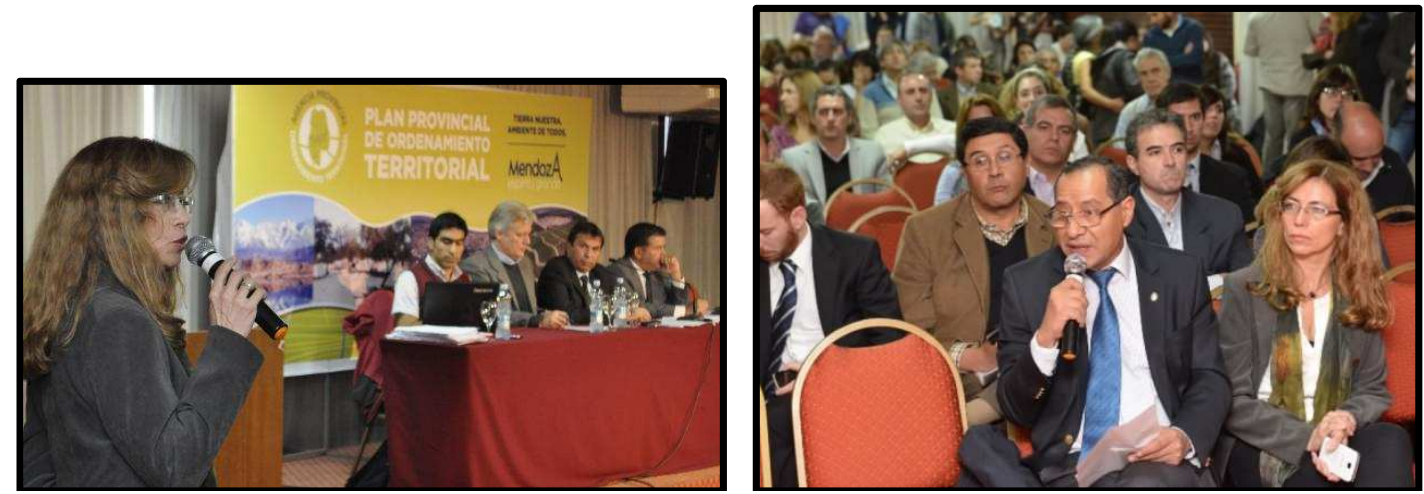

Figura 3

Referencia: Audiencia Pública. Centro de Congresos y Exposiciones. Mendoza. 15 de Abril 2014. 
Estas instancias de validación colectiva se realizaron en un contexto con determinas características y con actores representantes de sectores claves que es importante destacar para entender no sólo la forma en la que la Agencia de Ordenamiento Territorial ${ }^{2}$ trabajó $^{2}$ luego con los aportes al documento del PPOT, sino también los apoyos, objeciones y rechazos al documento y al proceso. Fundamentalmente en lo referido a la formas en las que se instrumentó la participación ciudadana.

El Ejecutivo había demostrado un notorio interés por cumplir rápidamente las etapas que la norma prevé. El gobernador había prometido presentar el Plan en el acto de apertura de sesiones ordinarias de la Legislatura y para ello era necesario validar previamente el documento, aunque esto significara desoír los reclamos de la ciudadanía que pedía más tiempo para analizar el material. "El período de consulta pública recién se habilitó esta semana -aunque el ministro Guillermo Elizalde planteó que evalúa la posibilidad de extenderlo- y es el paso previo a la audiencia pública prevista para el 27 de marzo. Esto, con el objetivo de llegar al 1 de mayo, como se comprometió el gobernador Francisco Pérez en la apertura de sesiones ordinarias -el mismo día del año pasado- con el proyecto de ley" (Diario Los Andes, 21/02/14).

La ciudadanía, por su parte, y principalmente los representantes de organizaciones no gubernamentales ambientalistas manifestaban su disconformidad con el proceso, llegando incluso a pedir la nulidad del mismo. Entre las principales críticas destacaban que el documento diagnóstico era muy extenso y poco legible y que además no contemplaba los aportes que la ciudadanía venía realizando en las diferentes instancias de participación a las que venían siendo convocados desde el 2012. "Ha habido espacios de participación y consulta permanentes, pero desconozco si las sugerencias se han visto plasmadas en este proyecto preliminar. No he podido leer todo el material, es complicado para quienes no han estado involucrados en su elaboración, con lo que se dificulta una Consulta Pública informada" (Ciudadana participante de los talleres en la etapa diagnóstica. Diario Los Andes, 21/02/14). Mientras una ciudadana integrante de la Asamblea por el Agua de San Carlos sostenía que: "hace dos años que venimos participando y nos encontramos con que el documento preliminar es un engendro que va mutando. Los mismos funcionarios no cumplen con los procedimientos. Evidentemente están apurados porque el gobernador les pidió presentar el proyecto el primero de mayo" (Diario Los Andes, 16/04/16).

Los partidos de la oposición también expresaron una postura crítica a la metodología utilizada para la elaboración del documento y a los contenidos del mismo. "El documento se muestra como un híbrido que no alcanza a constituirse como un plan, hay un listado de proyectos sin jerarquización, sin plazos, en fin un conjunto de obras que no contribuyen a la

\footnotetext{
${ }^{2}$ A cargo de la elaboración del documento del PPOT (art. 41).
} 
Mendoza del 2030" (Kotlik, Diego. Director de Planificación Urbana. Municipio de Godoy Cruz. En Diario Los Andes, 16/04/16).

El sector técnico-científico ${ }^{3}$ que había participado tanto en la elaboración de la Ley 8051, como en las etapas de elaboración del diagnóstico; el modelo territorial y los escenarios alternativos también mostraba su disconformidad por la forma en que dicho trabajo había sido plasmado, por la Agencia, en el documento preliminar del PPOT. Entre las apreciaciones de los expertos se sostenía que el diagnóstico realizado no se veía reflejado en el Plan (Coordinadora del Institutito de Ciencias Ambientales UNCuyo. En Diario Los Andes, 16/04/16) y que "el documento adolece de fallas técnicas e incoherencias" (Directora del Doctorado en Ordenamiento Territorial y Desarrollo Sustentable. UNCuyo. En Diario Los Andes, 16/04/16).

En definitiva, quienes venían participando en la implementación de las etapas previstas por la ley sostenían la necesidad de aprobar el plan. Desde el sector político oficialista porque les permitía capitalizar, previo a las elecciones del 2015, un proceso que venían impulsando desde la Secretaría de Medio Ambiente, desde el 2007. El gobierno sabía que se trataba de una política sensible a los intereses ciudadanos que transversaliza todo el territorio provincial e intenta ordenar la explotación de recursos vitales para la provincia, como son el agua y los minerales. En dicho sentido, repercute en los intereses de poderosos sectores, como son el inmobiliario y el de las empresas mineras. Mientras que desde el sector científico porque, más allá de las críticas a la metodología utilizada por la Agencia para la elaboración del Plan, habían sido parte no sólo de las etapas previas sino también de la elaboración de la Ley de Ordenamiento Territorial y Usos del Suelo y creían fundamental avanzar con el proceso.

Por otro lado, estaban quienes se oponían a la aprobación del documento preliminar presentado por el gobierno. El sector político de la oposición aducía fallas metodológicas en la elaboración del documento que no llegaba a constituir un plan; aparte de los intereses político-electorales que estaban en juego. $\mathrm{Y}$ los ciudadanos, principalmente los representantes de organizaciones ambientalistas, que con un altísimo nivel de organización, venían participando de todo el proceso y no veían que sus aportes fueran parte del documento que el gobierno pretendía ingresar a la Legislatura. La ley, en dicho sentido, tampoco establece una metodología que ayude a garantizar la incorporación de los aportes ciudadanos.

\footnotetext{
${ }^{3}$ Cuando hablamos del sector técnico-científico nos referimos fundamentalmente a los integrantes del Proyecto de Investigación y Desarrollo PID 08/2009: “Ordenamiento Territorial para un desarrollo sustentable". Financiado por el Fondo para la Investigación Científica y Tecnológica (FONCYT). Institución beneficiaria: Universidad Nacional de Cuyo (UNCuyo). Empresa adoptante: Secretaría de Medio Ambiente del Gobierno de Mendoza (actual Ministerio de Tierras, Ambiente y Recursos Naturales).
} 
A fin de plasmar estas distintas posturas y entender la lógica de un complejo proceso participativo, hemos sistematizado y cuantificado los aportes realizados por los actores en las tres instancias -Consulta Pública; CPOT; Audiencia Pública- de acuerdo a los siete procesos críticos identificados en el diagnóstico del Plan Estratégico de Desarrollo Mendoza 2030 (PEDMza 2030) a partir de los cuales se elaboró el documento preliminar del Plan Provincial de OT.

\begin{tabular}{|c|c|c|c|c|}
\hline Problema & $\begin{array}{l}\text { Consulta } \\
\text { Pública }\end{array}$ & $\begin{array}{c}\text { Audiencia } \\
\text { Pública }\end{array}$ & CPOT & $\begin{array}{l}\text { Total } \\
\text { participación } \\
\text { por problema }\end{array}$ \\
\hline $\begin{array}{l}\text { 1. Fortalecimiento institucional del rol del Estado a } \\
\text { partir de un sistema de gestión coordinada del } \\
\text { territorio con participación ciudadana como } \\
\text { mecanismo para garantizar el pleno ejercicio de los } \\
\text { derechos esenciales: agua, suelo, aire y el acceso a } \\
\text { un ambiente sano y seguro. }\end{array}$ & 8 & 42 & 10 & 50 \\
\hline $\begin{array}{l}\text { 2. Disminución de la fragmentación territorial, la } \\
\text { segregación socio-espacial y la exposición a los } \\
\text { riesgos frente a amenazas naturales y antrópicas. }\end{array}$ & 25 & 22 & 33 & 80 \\
\hline $\begin{array}{l}\text { 3. Desarrollo de una economía regional integrada y } \\
\text { diversificada, basada en la innovación, generadora } \\
\text { de empleo genuino a través de modalidades } \\
\text { productivas que agreguen valor territorial a lo largo } \\
\text { de toda la cadena de producción. }\end{array}$ & 9 & 6 & 12 & 27 \\
\hline $\begin{array}{l}\text { 4. Integración de nuestra provincia en América Latina e } \\
\text { inserción en el mundo, potenciando su posición } \\
\text { estratégica y su disponibilidad de recursos. }\end{array}$ & 1 & 0 & 8 & 9 \\
\hline $\begin{array}{l}\text { 5. Integración de las zonas no irrigada, mayor } \\
\text { eficiencia en la gestión de los oasis y reservación de } \\
\text { zonas agrícolas que prestan servicios ambientales, } \\
\text { conservando y promoviendo el patrimonio natural, } \\
\text { cultural, ambiental y paisajístico. }\end{array}$ & 7 & 5 & 13 & 25 \\
\hline $\begin{array}{l}\text { 6. Incorporación de nuevas propuestas educativas y } \\
\text { profesionales en función de un modelo territorial } \\
\text { sustentable, promoción de la investigación, el } \\
\text { desarrollo y la innovación en los sectores } \\
\text { estratégicos para el desarrollo provincial. }\end{array}$ & 1 & 2 & 1 & 4 \\
\hline $\begin{array}{l}\text { 7. Mayor eficiencia para un uso más equitativo del } \\
\text { recurso hídrico. }\end{array}$ & 8 & 13 & 8 & 29 \\
\hline Total participación por instancia & 59 & 90 & 75 & \\
\hline
\end{tabular}

Cuadro $\mathrm{N}^{\circ}$ 3: Sistematización y cuantificación de los aportes ciudadanos en función de los problemas identificados por el PPOT

Fuente: Elaboración propia a partir del documento preliminar Plan Provincial de OT. Pág. 40, 41 y de las Actas elaboradas por la Agencia Provincial de OT.

El procesamiento de los aportes ciudadanos en función de los ejes a partir de los cuales se elaboró el plan, nos permitió verificar cuáles son las problemáticas que más preocupan a la ciudadanía, hacia dónde el gobierno tendría que direccionar la política de ordenamiento territorial. 
En función de los datos presentados, entendemos que la ciudadanía mendocina reclama, en primera instancia, políticas tendientes a disminuir la fragmentación territorial y la segregación socio-espacial. Mendoza, como tantas otras urbes, no escapa a las problemáticas relacionadas al surgimiento de nuevas desigualdades en la estructura social y procesos de segregación -tanto material como simbólica- de amplios sectores históricamente subordinados, consecuencia de los procesos de precarización de los empleos industriales y de la consolidación del modelo de acumulación postfordista en los años 90. Procesos que sin duda impactan en el desarrollo del territorio contribuyendo a la emergencia de nuevos espacios cada vez más polarizados; es decir, más homogéneos hacia su interior y heterogéneos hacia el exterior (Dalla Torre, Ghilardi; 2012). El exponencial aumento de conjuntos inmobiliarios privados en los últimos años en la provincia es muestra de ello. Como así también lo es, el reclamo de los participantes por el desarrollo de una economía regional integral y diversificada que genere trabajo genuino.

En segundo lugar, la sociedad distingue al Estado como un actor central reclamándole un mayor involucramiento en la garantía de derechos esenciales como son el agua, el suelo, el aire y el ambiente. No es de extrañar que esto sea así en una provincia desértica que vive y se desarrolla a partir de sus oasis donde existe una cultura ciudadana altamente movilizada a torno al cuidado del agua y en contra de la minería.

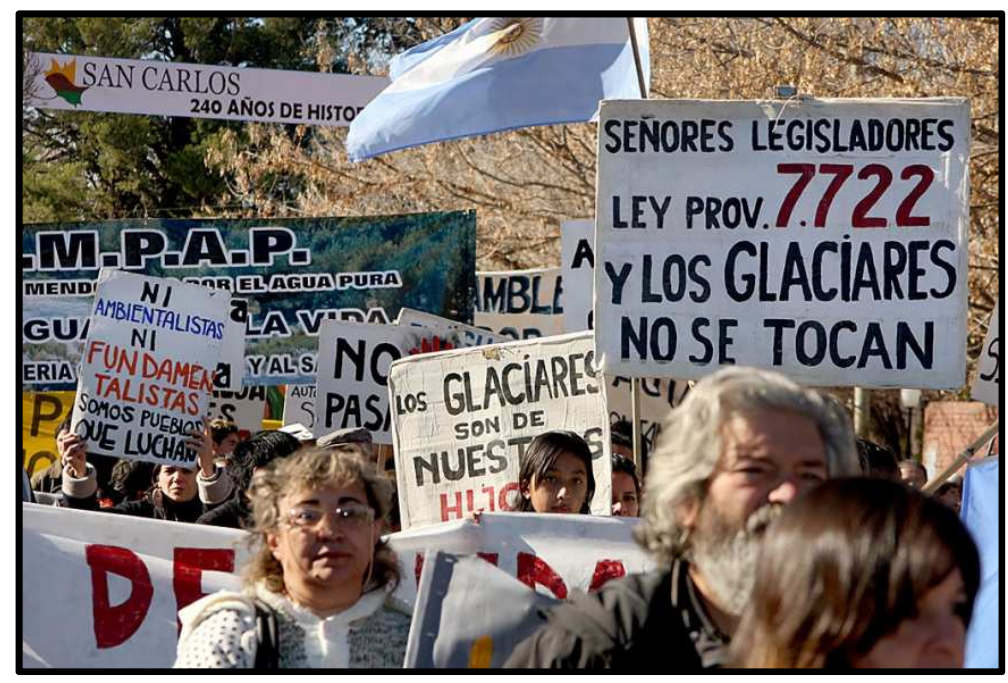

Figura 4

Referencia: Movilización de organizaciones ambientalistas de Mendoza en defensa del agua y en contra de la minería.

De hecho, las otras problemáticas a las que los ciudadanos y ciudadanas hacen mayor referencia también tienen que ver con esta preocupación relacionada al manejo y cuidado del recurso hídrico, la protección de los oasis irrigados y de las tierras con permiso de riego 
agrícola, en una provincia que hace, por cuarto año consecutivo, se encuentra en emergencia hídrica.

\section{El Plan Provincial de Ordenamiento Territorial}

Tal como el gobierno lo venía anunciando, el 1 de mayo de 2014 en el discurso de apertura del período de sesiones ordinarias de la Legislatura, el Gobernador, Dr. Francisco Pérez anunció que el Ejecutivo había enviado el día 30 de abril el proyecto de Ley para la aprobación del PPOT.

De acuerdo a este actor clave de la política, se habían cumplido las etapas previstas por la norma (ver cuadro № 1); en la Audiencia Pública la ciudadanía había dado su conformidad al proyecto: "se concluyó mayoritariamente, apoyar el Plan con observaciones y aportes, las que posteriormente han sido incorporadas por la Agencia de Provincial de Ordenamiento Territorial" (Expte. №65017/14) y el finalmente el CPOT, en sesión extraordinaria del 24 de abril, había aprobado la nueva versión del Plan "surgido de la participación y la construcción colectiva de provincia a la que se aspira" (Expte. №65017/14).

Sin embargo, representantes de la ciudadanía, de la oposición y del sector técnico científico sostenían que sus aportes no habían sido incorporados al documento del plan. Lo cual terminó sin duda afectando su tratamiento legislativo...

\section{1. ¿Cómo se elaboró el Plan?}

En esta etapa, la Agencia de Ordenamiento Territorial fue la responsable de la elaboración del documento del plan a partir del diagnóstico y del modelo deseado que habían sido construidos con la participación del sector técnico-científico, más los aportes de la CPOT y de la ciudadanía a través de la Consulta y la Audiencia Pública.

El proyecto de 160 páginas que fue presentado a la Legislatura se estructura en cinco capítulos: introducción; antecedentes; modelos territoriales; nodos a identificar y jerarquizar e instrumentos. Más un glosario y un anexo cartográfico.

Dentro del capítulo 3 se retoma el modelo territorial actual, el tendencial, el deseado y finalmente el realizable. Recordemos que, en la etapa diagnóstica, la Agencia, recurrió a los siete procesos críticos identificados en el PEDMza 2030. "El modelo deseado se construyó a partir de los procesos críticos identificados en el diagnóstico del PEDMza 2030 sin incorporar los diagnósticos situacionales desarrollados para cada subsistema y sin tener en cuenta los 
aportes de la ciudadanía a través de los talleres realizados por los equipos del sector técnicocientífico" (Guardamagna, Cueto, 2015: 148).

A partir de estos siete problemas (ver Anexo № 1) se planteó el modelo territorial deseado. Evidenciando una vez más, y tal como ya venía ocurriendo en las etapas previas, inconsistencias entre la secuencia definida por la norma y lo efectivamente implementado. Recordemos que de acuerdo a la Ley 8051/09 el modelo deseado debía surgir del diagnóstico (ver Cuadro № 1) y no del PEDMza 2030 que es anterior a esta etapa y que además es uno de los instrumentos y procedimientos del OT (art. 7. Ley 8051/09).

La situación deseada definida en el documento del plan merece algunos comentarios. Se trata de un planteo con un altísimo nivel de generalidad, confusión en las ideas y los conceptos utilizados y sin una bajada empírica clara, que permita a los ciudadanos y ciudadanas entender hacía dónde el gobierno propone el desarrollo territorial de la provincia. Por ejemplo, se enuncia que: "Desde el Estado provincial y municipal, así como en la construcción de políticas de Estado de extendido consenso entre los diversos sectores de la sociedad, se hace efectiva la inclusión social de todos los ciudadanos y ciudadanas para lograr la cohesión social, a través del trabajo digno, la educación, la salud, la vivienda en un hábitat adecuado, la cultura, la recreación y el deporte y el ambiente sano y seguro" (Documento PPOT, 2014: 34, 35).

En cuanto a los contenidos del modelo deseado, dentro de cada uno de los siete procesos críticos se mezclan diversas problemáticas. Dentro del primer problema que tiene que ver con la inercia en la gestión del Estado, se hace mención al sistema impositivo provincial, para pasar luego a las regalías provenientes de los recursos naturales no renovables y a continuación al personal del Estado: "Se promueve que el sistema impositivo provincial sea equitativo, previsible, que aliente la inversión, la creación de empleo y la redistribución de ingresos en lo social y territorial, el cumplimiento de las obligaciones fiscales es una conducta valorada socialmente. Se orientan las regalías provenientes del aprovechamiento de recursos naturales no renovables hacia el desarrollo sustentable de la provincia. Se promueve que el personal del Estado sea suficiente, idóneo, con capacitación permanente y con un sistema de ingreso, evaluación y promoción transparente" (Documento PPOT, 2014: 34).

Lo mismo ocurre con el resto de los problemas, donde se agrupan cuestiones como el transporte, la energía, la educación, el cambio climático, el respeto por la cultura de los pueblos, entre otras tantas cuestiones, que además se repiten en los distintos procesos críticos. Se trata también de problemas que requieren distintos niveles de análisis y abordaje, aunque no lo pareciera en la forma en la que son presentados: "Se diseñan $e$ implementan políticas públicas que garantizan la inclusión económica, política e 
institucional, profundizando la inversión social en el territorio y fortaleciendo y promocionando la familia en sus diversas formas. Se busca a través de políticas específicas el reposicionamiento del trabajo como integrador social por excelencia, que posibilita la construcción de identidad, que permite el acceso a los derechos y la asunción de obligaciones que representan un núcleo de inclusión y pertenencia social. Se promueve activamente la educación como garante de la movilidad social ascendente y generadora de oportunidades. Se hace una reparación histórica con los pueblos originarios reconociendo su derecho a la propiedad de la tierra y a recibir asistencia técnica y financiera para lograr un armónico desarrollo de sus actividades" (Documento PPOT, 2014: 35).

Este nivel de confusión se traslada luego al modelo territorial realizable. Nuevamente se definen siete ejes, que siguiendo la secuencia lógica utilizada en la etapa diagnóstico y en el modelo deseado deberían corresponderse con los siete procesos críticos previamente identificados. Sin embargo, se plantea una redefinición en el contenido de los ejes, algunos coincidentes con los problemas surgidos del diagnóstico, otros no.

A continuación la parte central del plan donde se definen los contenidos básicos en respuesta al artículo 21 de la Ley 8051 responde a la siguiente secuencia. En primer lugar, por cada uno de los ejes se definen objetivos específicos a alcanzar por el plan provincial y los planes municipales. Luego, para de cada uno de estos se establece un conjunto de directrices, lineamientos y programas. Dentro de los programas, se ponderan aquellos que son estructurantes ${ }^{4} \mathrm{y}$ finalmente, los que son prioritarios 0 indicativos ${ }^{5}$, que son los primeros que se implementarían a partir de la aprobación del PPOT. Sin embargo, en el documento no queda clara la distinción entre ambos tipos proyectos.

La cuantificación de la secuencia utilizada para la elaboración del PPOT nos permite apreciar la escasa sistematicidad y consistencia metodológica en la definición de las directrices, lineamientos y programas. El caso más significativo, en este sentido, es el del eje II, donde de 6 directrices, se desprenden 4 lineamientos y 26 programas, de los cuales, finalmente, se ejecutarán en forma prioritaria, solo 3.

Al analizar los contenidos de la misma, se evidencia además un alto nivel de generalidad, abstracción y desarticulación. De hecho no queda clara la distinción entre lo que se entiende por directriz y por lineamiento, ya que ambos se caracterizan por un mismo estado de generalidad.

\footnotetext{
${ }^{4}$ Los programas estructurantes "se conciben de realización prioritaria para la concreción de los objetivos del PPOT" (Documento Plan Provincial de OT, 2014: 50).

${ }^{5}$ Programas estructurantes prioritarios e indicativos: "si bien los programas serán desarrollados a partir de la aprobación del PPOT, se definen los considerados estructurantes prioritarios detallando: objetivo, breve descripción, actores intervinientes y plazos para su elaboración, desarrollo e implementación" (Documento Plan Provincial de OT, 2014: 59).
} 


\begin{tabular}{|c|c|c|c|c|c|c|}
\hline Ejes & $\begin{array}{c}\text { Objetivos } \\
\text { específicos a } \\
\text { alcanzar por el } \\
\text { PPOT y PMOT } \\
\text { por Eje }\end{array}$ & $\begin{array}{l}\text { Directrices } \\
\text { por objetivo }\end{array}$ & $\begin{array}{l}\text { Lineamientos } \\
\text { por objetivo }\end{array}$ & Programas por objetivo & $\begin{array}{c}\text { Programas } \\
\text { Estructurantes } \\
\text { por objetivo }\end{array}$ & $\begin{array}{c}\text { Programas } \\
\text { Estructurantes } \\
\text { Prioritarios o } \\
\text { Indicativos por } \\
\text { objetivo }\end{array}$ \\
\hline 1 & 1 & 5 & 7 & 3 & 3 & 3 \\
\hline II & 1 & 6 & 4 & $\begin{array}{l}\text { Nodo principal: } 7 \\
\text { Centros intermedios: } 4 \\
\text { Centros rurales: } 3 \\
\text { Creación polos } \\
\text { desarrollo: } 5 \\
\text { Generales: } 7 \\
\text { Total: } 26\end{array}$ & 5 & 5 \\
\hline III & 1 & 7 & 4 & 12 & 4 & 4 \\
\hline IV & 1 & 9 & 5 & 14 & 3 & 3 \\
\hline $\mathrm{V}$ & 1 & 3 & 4 & 9 & 2 & 2 \\
\hline $\mathrm{VI}$ & 1 & 5 & 5 & 6 & 2 & 2 \\
\hline VII & 1 & 3 & 4 & 12 & 2 & 2 \\
\hline
\end{tabular}

Cuadro № 4: Cuantificación de la secuencia utilizada en la elaboración del plan

Fuente: elaboración propia a partir del documento del Plan Provincial de OT.

Por su parte, la extensa enunciación de programas por eje es repetitiva y con un altísimo nivel de abstracción. Una breve enunciación así lo demuestra: Programas del eje II: "programa de movilidad sustentable; programa de infraestructura; programa de vivienda y hábitat; programa de servicios; programa de equipamiento...." (Documento Plan Provincial de OT, 2014: 44). Programas del eje III: "programa de inserción, integración y de mixtura de sectores sociales; programas de barrios; programa de seguridad humana; programa de acceso al empleo..." (Documento Plan Provincial de OT, 2014: 45, 46).

Sumado a lo cual, en el documento sólo se llega al nivel de programas, más allá de que la ley define a lo largo de todo su texto la necesidad de "implementar planes, programas $y$ proyectos" (ver Ley 8051). En definitiva, el proyecto del PPOT no propone una bajada empírica que oriente a los municipios para el desarrollo de sus propios planes y a la ciudadanía un panorama entendible de hacía dónde el gobierno está pensando el desarrollo de la provincia. El documento tampoco evidencia la priorización de las problemáticas realizada por la ciudadanía en las instancias consultivas -Consulta y Audiencia Pública-.

\subsection{Similitudes y diferencias con el proyecto del sector científico}

A principios del 2014 representantes del sector técnico-científico, miembros del Proyecto de Investigación y Desarrollo PID 08/2009: “Ordenamiento Territorial para un desarrollo sustentable" Uncuyo-Conicet, fueron convocados nuevamente por el Gobierno con la intención mejorar el material que iba a ser puesto a discusión de la ciudadanía en la Audiencia Pública. Sin embargo, en el mes de julio de 2014, tres meses después de que el 
Gobierno remitiera a la Legislatura el PPOT, este mismo grupo de especialistas ingresa para su tratamiento otro documento con aspectos que a su entender no habían sido incorporados al proyecto oficial que a su entender constituía una versión acotada del original omitiendo además el tratamiento de aspectos que están normados por la Ley 8051/09.

El nuevo documento respondía "al Reglamento para la elaboración del Plan Provincial de Ordenamiento Territorial, aprobado por el CPOT en el mes de marzo del 2014 e incorpora los aportes brindados por la Agencia y el Sistema de Información Ambiental Territorial (SIAT) del Ministerio de Tierras, Ambiente y Recursos Naturales del Gobierno de Mendoza; los dictámenes del CPOT; los aportes efectuados en la Consulta Pública hecha durante el mes de febrero de 2014 y los aportes a la Audiencia pública realizada el 15 de abril de 2014" (Nota elevada por Gudiño a la Honorable Cámara de Senadores. Mendoza, 04/07/14) que a su entender no habían sido totalmente incorporados al proyecto oficial.

Ahora bien, ¿̇uáles son los principales puntos de disidencia de este proyecto con el oficial? Para distinguirlos hemos confrontado ambos proyectos (ver Anexo № 2), recurriendo además a los documentos donde el grupo de especialistas responsable de su elaboración resalta las diferencias entre ambos, poniendo especial atención a aquellas relacionadas con los aportes de la ciudadanía. Estas se refieren a cuestiones de forma y de contenido. Entre las primeras podemos mencionar que:

- El PPOT omite las previsiones del Reglamento aprobado por el CPOT; no incluye el diagnóstico construido participativamente a partir de lo establecido por la Ley 8051; tampoco considera en su totalidad las etapas definidas para la elaboración del Plan aprobadas en plenario del CPOT (Nota elevada por Gudiño a la Honorable Cámara de Senadores. Mendoza, 04/07/14).

- La propuesta de los especialistas de la UNCuyo-Conicet ${ }^{6}$ incorpora cronogramas de acciones de los programas e instrumentos vinculados a los Planes Municipales (Propuesta Plan Provincial de OT. UNCuyo-Conicet, 2014: 103, 104).

Dentro de las disidencias de contenido:

- El PPOT no responde a la metodología que la Universidad Nacional de Cuyo aportó validada a través de talleres participativos en todo el territorio provincial (Nota elevada por Gudiño a la Honorable Cámara de Senadores. Mendoza, 04/07/14). Esto más allá de lo que el proyecto del Ejecutivo hace mención a la metodología "adoptada" (ver documento Plan Provincial de OT, 2014: 15).

\footnotetext{
${ }^{6}$ Universidad Nacional de Cuyo-Consejo Nacional de Investigaciones Científicas y Técnicas.
} 
- El PPOT no establece criterios técnico-científicos que garanticen homogeneidad procedimental para la planificación territorial coordinada de las instituciones gubernamentales que participan en la implementación de la política (Nota elevada por Gudiño a la Honorable Cámara de Senadores. Mendoza, 04/07/14).

- Varía la cantidad y el contenido de los programas. La propuesta de los especialistas de la UNCuyo-Conicet define directamente los programas que considera estructurantes ${ }^{7}(12)$ (Propuesta Plan Provincial de OT. UNCuyo-Conicet, 2014: 32, 33). Los mismos incluyen objetivos a alcanzar; instituciones responsables; zonas en las que se desarrollarán; procedimientos a cumplir por cada institución; etapas y tiempos previstos y las probables fuentes de financiamiento. La propuesta de plan del Gobierno propone 82 programas que "son solo indicativos contrariamente a lo que exige la ley no 8051" (Nota elevada por Gudiño a la Honorable Cámara de Senadores. Mendoza, 04/07/14) y que luego reducen a 21 programas estructurantes (Documento Plan Provincial de OT, 2014: 41-66). Por cada programa estructurante, se definen objetivo; descripción; actores intervinientes y plazos. No se mencionan fuentes de financiamiento o partidas presupuestarias específicas para la concreción de cada programa.

- El proyecto presentado por el grupo de científicos de la UNCuyo-Conicet incorpora, a los instrumentos de la Consulta pública y Audiencia Pública, mecanismos para la difusión de los resultados de las evaluaciones (Propuesta Plan Provincial de OT. UNCuyo-Conicet, 2014: 101).

- Varía la definición de los Instrumentos de Gestión, Ejecución y Control. El proyecto del Gobierno enuncia los siguientes: la Auditoría Interna (Al); la Auditoría Externa de Impacto Territorial (AEIT); la Evaluación de Impacto Territorial (EIT) y la Evaluación Ambiental Estratégica (EAE) (Documento Plan Provincial de OT, 2014: 110). El documento de los especialistas del sector técnico-científico, además de hacer mención a los mismos instrumentos, propone la elaboración de Planes de acción anual por resultados en materia de Ordenamiento Territorial; Convenios Interjurisdiccionales que permitan lograr consistencia e integralidad de las políticas; define recursos económicos para la implementación del plan, de acuerdo a lo dispuesto por el artículo 51 de la Ley 8051/09 y los del Fondo de Afectación Específica (art. 53) para los municipios (Propuesta Plan Provincial de OT. UNCuyo-Conicet, 2014: 90-96).

- Varía la definición de la zonificación definida por la Ley 8051/09 (art. 15) como instrumento del ordenamiento y la planificación territorial. En el proyecto del sector

\footnotetext{
${ }^{7}$ Definen como programas estructurantes a aquellos con cuya ejecución se tiende a modificar la forma de organización del territorio para el logro de una mayor integración, equilibrio, equidad y sustentabilidad. Son programas concadenados entre sí y con los instrumentos previstos para su implementación (Nota elevada por Gudiño a la Honorable Cámara de Senadores. Mendoza, 04/07/14).
} 
técnico-científico se incluye la metodología para que los municipios puedan realizarla y los criterios generales y uniformes para delimitar la unidad urbana; las áreas de interface; las naturales; las rurales y las sujetas a regímenes especiales (Propuesta Plan Provincial de OT. UNCuyo-Conicet, 2014: 75-78).

- Con respecto a los conjuntos inmobiliarios ${ }^{8}$ y de los cementerios privados se hacen previsiones expresas que se corresponden con lo exigido por el artículo 11 de la Ley $\mathrm{N}^{\circ}$ 8051. Respecto de los primeros se llega a la conclusión que el desorden prevaleciente obedece a una anacrónica interpretación de la Ley de Loteos de la Provincia por lo que se propone habilitar la figura de la propiedad horizontal como forma jurídica que pueden adoptar estos conjuntos inmobiliarios. Además se define como área permitida para los mismos, la urbana y de interfase, promoviendo así la protección del área rural del avance de los mismos (Propuesta Plan Provincial de OT. UNCuyo-Conicet, 2014: 71-73). El tema no es abordado por el proyecto del Ejecutivo.

\section{Conclusiones}

Desde el año 2014 ambos proyectos del PPOT -el presentado por el gobierno provincial y el del sector técnico científico- se encuentran en estudio en la Comisión de Ambiente del Senado. Es decir que están prácticamente paralizados, más allá de los infructuosos intentos del gobierno saliente por aprobarlo antes de la asunción de las nuevas autoridades en diciembre de 2015. Se abre en este sentido un panorama incierto para el futuro de la política de ordenamiento territorial, teniendo en cuenta que el gobierno actual fue uno de los principales opositores al proyecto que hoy se encuentra en el poder legislativo.

La secuencia analizada en el presente trabajo, desde el modelo deseado a la elaboración del plan, pasando por las instancias de participación ciudadana, deja en evidencia, tal como ocurrió en las etapas anteriores, la complejidad de un proceso cargado de tensiones, conflictos e inconsistencias, tanto en lo referido a las formas como en los contenidos.

En dicho sentido se evidencia que:

El excesivo normativismo que define la Ley 8051 en vez de facilitar y garantizar la ejecución de la política, complejiza aún más el proceso, generando brechas entre la etapa de formulación y la implementación de la misma. Poniendo además en peligro su contenido sustancial que tiene que ver en definitiva con resguardar los recursos naturales $y$, por lo

\footnotetext{
${ }^{8}$ Cabe aclarar que el Área Metropolitana de Mendoza tiene la mayor cantidad de barrios privados del país, luego del Gran Buenos Aires (Unidiversidad, 2015).
} 
tanto, la calidad de vida de los mendocinos. Se trata de una característica de la ley que le resta flexibilidad y capacidad de adaptación a una política, que de por sí es compleja.

En general, las etapas definidas por la norma se cumplieron en lo formal. Sin embargo, las inconsistencias teórico-metodológicas que marcábamos en la elaboración de los diagnósticos situacionales y su posterior articulación para la construcción del modelo actual de la provincia (Guardamagna, Cueto, 2015) siguen presentes en la etapa de elaboración del plan.

Dentro de las observaciones que el sector técnico-científico hace respecto a las omisiones del documento oficial, algunas de las más significativas para la política tienen que ver con que no se definen recursos económico-financieros ni se asignan partidas presupuestarias específicas para la concreción de los programas estructurantes. Tampoco se define una metodología para la zonificación a fin de aplicar criterios homogéneos en todo el territorio provincial. Temas que sin duda atraviesan intereses políticos y económicos de los actores y sectores afectados por la política....

Finalmente, las críticas de los principales afectados por esta política, la ciudadanía, se refieren principalmente al modo cómo se instrumentó la participación y la incorporación de sus aportes al documento del PPOT. La Consulta y la Audiencia Pública, en relación a los talleres que se venían realizando en los distintos departamentos, sirvieron, en dicho sentido, para poner en evidencia a los distintos actores de la sociedad civil, sus críticas, apoyos y rechazos.

Aparece aquí uno de los desafíos, a nuestro entender, no resueltos por la política de ordenamiento territorial. Una política que define a la participación ciudadana como un elemento central, pero que, hasta ahora, sólo ha logrado garantizarla en lo formal...

Es necesario avanzar en la efectiva articulación de la participación y los aportes ciudadanos, de lo contrario se corre el riesgo de generar un efecto contrario en los participantes que no se sienten escuchados y hasta "estafados" por haber concurrido sin sentido. En esto las metodologías, recurso tiempo y la decisión política son claves. De lo contrario nos inclinaremos a pensar, como Rodríguez y Saavedra (2006) al decir que la autoridad realiza estas instancias de participación ciudadana sabiendo que los aportes de la sociedad podrán o no ser considerados y que, en todo caso, difícilmente cambiarán el sentido de la planeación del Estado... 


\section{Referencias bibliográficas}

CUETO, Walter y GUARDAMAgNA, Melina. ¿Hay políticas de Estado en la Argentina? Aproximaciones a un concepto. Revista Documentos y Aportes en Administración Pública y Gestión Estatal. 2012. Año 12 . № 18. Universidad Nacional del Litoral. Santa Fe. Argentina. ISSN 1666-4124. Pp. 7-26.

DALLA TORRE, Julieta y GHILARDI, Matías. Aproximación a la ciudad dual. Fragmentación espacial y segregación material y simbólica en el Área Metropolitana de Mendoza, Argentina. Revista Proyección. 2012. № 12. Instituto CIFOT ISSN: 1852 0006. Publicación digital.

DIARIO LOS ANDES. Amplían aportes a plan de uso del suelo. Viernes 21 de Febrero de 2014. Versión impresa.

DIARIO LOS ANDES. Es importante que participes del ordenamiento territorial en Mendoza. Domingo 16 de Febrero de 2014. Versión impresa.

DIARIO LOS ANDES. Inédita discusión por el uso del suelo. Miércoles, 16 de Abril de 2014. Versión impresa.

DIARIO LOS ANDES. No fue aprobado, pero ya genera polémica el plan de ordenamiento. Domingo 13 de Julio de 2014. Versión impresa.

ELIZALDE, Guillermo. El desafío de ordenar el territorio. En Diario Los Andes. Sábado 28 de Junio de 2014. Versión impresa.

GUARDAMAGNA, Melina y CUETO, Walter. Políticas de Estado en democracia: la relación Estado Sociedad como ámbito de construcción de la política. Revista Si Somos Americanos. Revista de Estudios Transfronterizos. 2013. Volumen XIII / N² / julio - diciembre. Universidad Arturo Prat. Santiago de Chile. ISSN 0718-2910. Pp. 59-80.

GUARDAMAGNA, Melina y CUETO, Walter. La implementación de la Política de Ordenamiento Territorial en Mendoza, Argentina: una mirada crítica sobre diseño del Plan Provincial. Revista Enfoques. 2015. 13(22). Santiago de Chile. [Abril, 2016]. Disponible en: dehttp://www.revistaenfoques.cl/index.php/revistauno/article/view/335. ISSN 0718-9656 versión en línea. ISSN 0718-0241 versión impresa. Pp. 135-153.

Ley N²051. 2009. Ordenamiento Territorial y Usos del Suelo. Provincia de Mendoza.

MANERO MIGUEL, Fernando. La participación ciudadana en la ordenación del territorio: posibilidades y limitaciones. Cuadernos Geográficos. 2010. 47. Universidad de Granada. España. ISSN: 0210-5462. Pp. 47-71.

MARTÍNEZ FLORES, Verónica y otros. Participación ciudadana y planeación del ordenamiento territorial en la frontera norte de México. Revista Espiral. Estudios sobre Estado y Sociedad. 2005. Vol. XXII No. 64 Septiembre/ Diciembre. Universidad de Guadalajara. México. ISSN: 1665-0565.

Nota presentada por los especialistas de CONICET y la Universidad Nacional de Cuyo al Presidente de la Comisión de Ambiente. Senado de la Legislatura de la Provincia de Mendoza. 4 de Julio de 2014.

Plan Provincial de Ordenamiento Territorial. Proyecto elaborado por especialistas de CONICET y la Universidad Nacional de Cuyo. Presentado a la Legislatura Provincial. Julio 2014.

Plan Provincial de Ordenamiento Territorial. Documento preliminar presentado a la Audiencia Pública. Enero, 2014.

Plan Provincial de Ordenamiento Territorial. Proyecto presentado por el Gobierno de Mendoza a la Legislatura Provincial. Expediente Nro.: 65017. 30 de Abril 2014.

Proyecto no 06/F334. La implementación de una política pública en contexto de complejidad normativa: el caso del ordenamiento territorial en Mendoza a partir de 2009. Secretaría de Ciencia, Técnica y Postgrado. UNCuyo. Programa de Incentivos 2013/2015.

RODRÍGUEZ Vera, RUBÉN Alfonso y SAAVEDRA DE LA CRUZ, Gustavo. La participación social en el ordenamiento territorial. Participación o representación un dilema legal y metodológico. En AGUILAR 
ROBLEDO, Miguel y otros. Ordenamiento territorial y participación social: problemas y posibilidades. 1은 edición. México. INECC. 2012. Capítulo 9. Pp. 241-269.

SATLARI, G.; DI PIETRO, M; ROdRíGUEZ AGUILERA, P; FEMENÍA, A; SCHILARDI, C; RAMAZZI, F; GILI, G y L. IRUSTA. Relevamiento de la infraestructura de riego de la provincia de Mendoza y su sistematización en un sistema de información geográfico. 2005. Departamento General de Irrigación. Mendoza. Argentina.

SUBIRATS, KNOEPFEL, LARRUE y VARONNE. Análisis y gestión de políticas públicas. Barcelona. Ariel. 2008. ISBN $8434400103,9788434400108$.

UNIDIVERSIDAD. La década loteada, un mapa de los barrios cerrados de Mendoza. 2015. [Junio, 2016]. Disponible en: http://www.unidiversidad.com.ar/ladecadaloteada. 


\section{Anexos:}

Anexo 1: Prueba de inconsistencia metodológica en la secuencia entre el diagnóstico y el plan

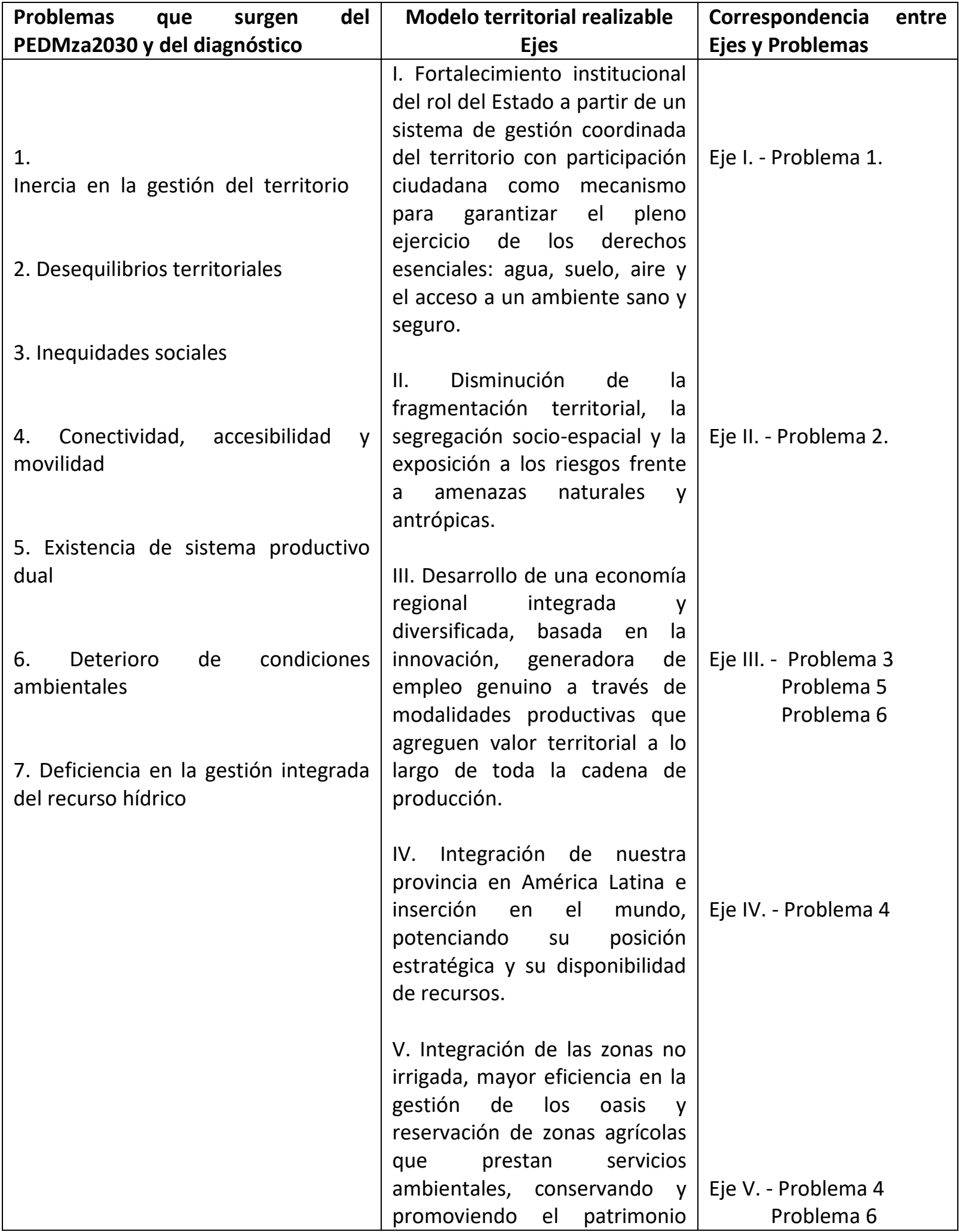




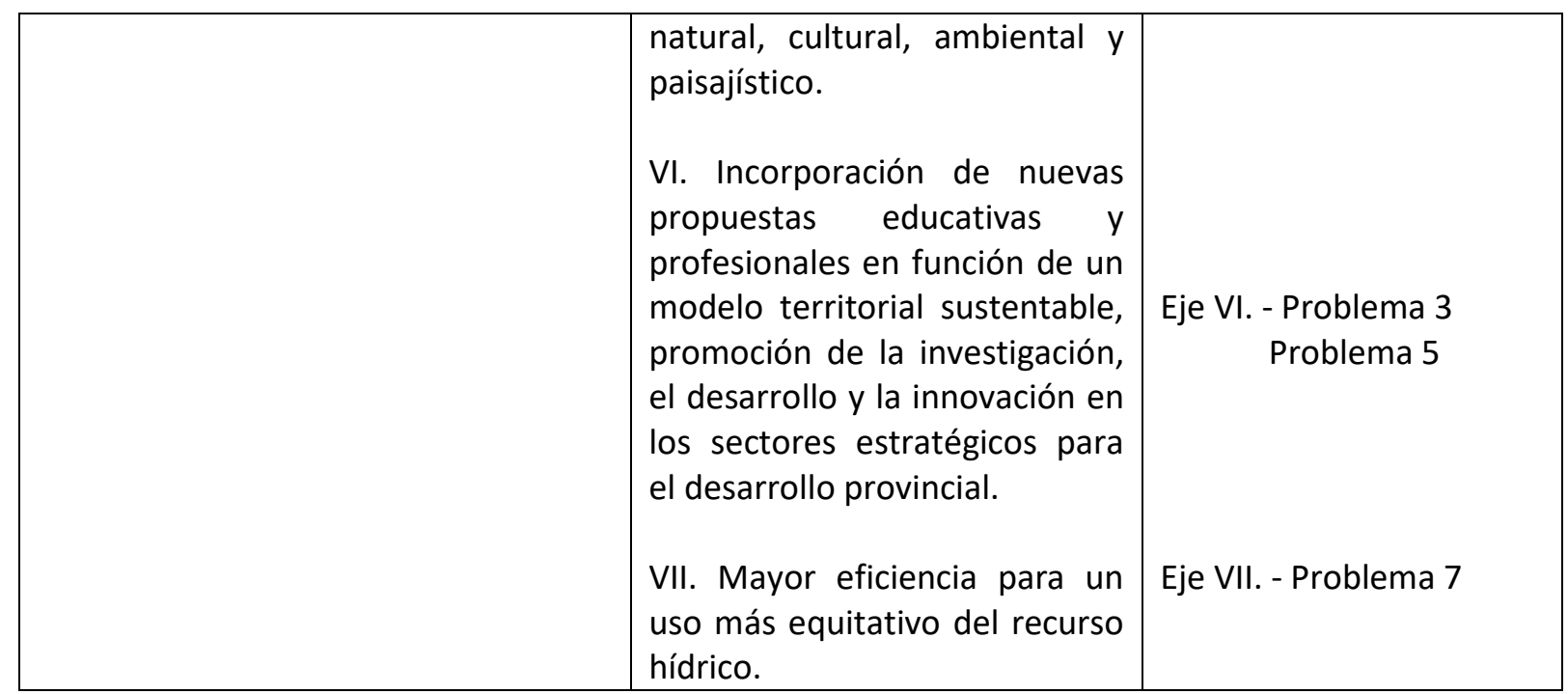

Fuente: elaboración propia a partir del documento del Plan Provincial de OT. 
Anexo № 2: Comparativa entre el proyecto de PPOT del Poder Ejecutivo y el de especialistas del sector técnico-científico:

Ejes y programas estructurantes

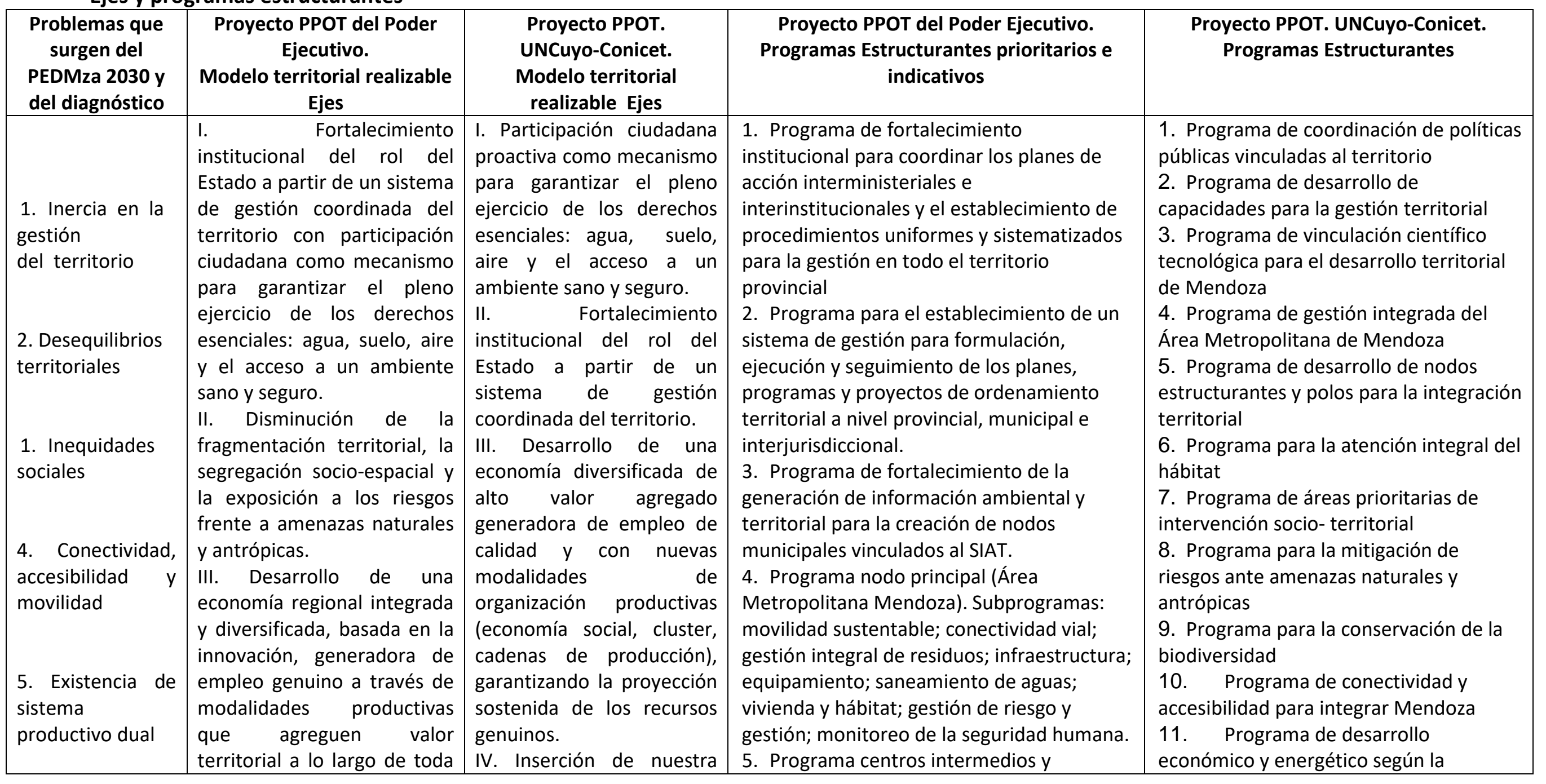




\begin{tabular}{|c|c|c|c|c|}
\hline $\begin{array}{l}\text { 6. Deterioro de } \\
\text { condiciones } \\
\text { ambientales } \\
\text { 7. Deficiencia en } \\
\text { la gestión } \\
\text { integrada del } \\
\text { recurso hídrico }\end{array}$ & $\begin{array}{l}\text { la cadena de producción. } \\
\text { IV. Integración de nuestra } \\
\text { provincia en América Latina } \\
\text { e inserción en el mundo, } \\
\text { potenciando su posición } \\
\text { estratégica y su } \\
\text { disponibilidad de recursos. } \\
\text { V. Integración de las zonas } \\
\text { no irrigada, mayor eficiencia } \\
\text { en la gestión de los oasis y } \\
\text { reservación de zonas } \\
\text { agrícolas que prestan } \\
\text { servicios ambientales, } \\
\text { conservando y promoviendo } \\
\text { el patrimonio natural, } \\
\text { cultural, ambiental y } \\
\text { paisajístico. } \\
\text { VI. Incorporación de nuevas } \\
\text { propuestas educativas y } \\
\text { profesionales en función de } \\
\text { un modelo territorial } \\
\text { sustentable, promoción de la } \\
\text { investigación, el desarrollo y } \\
\text { la innovación en los sectores } \\
\text { estratégicos para el } \\
\text { desarrollo provincial. } \\
\text { VII. Mayor eficiencia para un } \\
\text { uso más equitativo del } \\
\text { recurso hídrico. }\end{array}$ & $\begin{array}{l}\text { provincia en América } \\
\text { Latina y el mundo gracias a } \\
\text { su posición estratégica. } \\
\text { V. Integración de las zonas } \\
\text { no irrigadas, mayor } \\
\text { eficiencia en el manejo del } \\
\text { agua en los oasis y } \\
\text { preservación de zonas } \\
\text { agrícolas que prestan } \\
\text { servicios ambientales. } \\
\text { VI. Disminución de la } \\
\text { fragmentación } \\
\text { socioterritorial y de los } \\
\text { riesgos frente amenazas } \\
\text { naturales y antrópicas. } \\
\text { VII. Valoración de la } \\
\text { identidad cultural y } \\
\text { patrimonial. } \\
\text { VIII. Mayor eficiencia para } \\
\text { un uso más equitativo del } \\
\text { recurso agua. } \\
\text { IX. Incorporación de nuevas } \\
\text { estrategias educativas y } \\
\text { profesionales en función } \\
\text { del perfil productivo } \\
\text { provincial. } \\
\text { X. Promoción de la } \\
\text { investigación y } \text { de } \\
\text { desarrollo en sectores } \\
\text { estratégicos }\end{array}$ & $\begin{array}{l}\text { menores. Subprogramas: equipamiento, } \\
\text { infraestructura; servicios; vivienda y hábitat } \\
\text { 6. Programa centros rurales. } \\
\text { Subprogramas: dotación de servicios básicos } \\
\text { (agua y luz); dotación de equipamiento, } \\
\text { infraestructura y servicios; vivienda y hábitat } \\
\text { rural. } \\
\text { 7. Programa polos de desarrollo. } \\
\text { Subprogramas: conectividad y accesibilidad; } \\
\text { energía; equipamiento; infraestructura; } \\
\text { servicios; vivienda y hábitat; TICs. } \\
\text { 8. Programa protección y puesta en valor } \\
\text { de los suelos productivos y de las áreas de } \\
\text { fragilidad ambiental. } \\
\text { 9. Programa refuncionalización y expansión } \\
\text { de los servicios } \\
\text { 10.Programa banco de tierras fiscales } \\
\text { 11.Programa barrios } \\
\text { 12.Programa acceso al empleo } \\
\text { 13.Programa generación de indicadores } \\
\text { ambientales } \\
\text { 14.Programa determinación de los valores } \\
\text { de aptitud del suelo y capacidad de carga } \\
\text { 15.Programa mitigación de riesgos ante } \\
\text { amenazas naturales y antrópicas (Plan de } \\
\text { gestión de riesgo) } \\
\text { 16.Programa accesibilidad y conectividad } \\
\text { local, provincial, nacional e internacional } \\
\text { acorde con el modelo deseado de la } \\
\text { provincia } \\
\text { 17.Programa unificación de los servicios de } \\
\text { transporte público de pasajeros en una red }\end{array}$ & $\begin{array}{l}\text { vocación del territorio } \\
12 . \quad \text { Programa para la gestión } \\
\text { integrada y participativa del agua y del } \\
\text { territorio }\end{array}$ \\
\hline
\end{tabular}




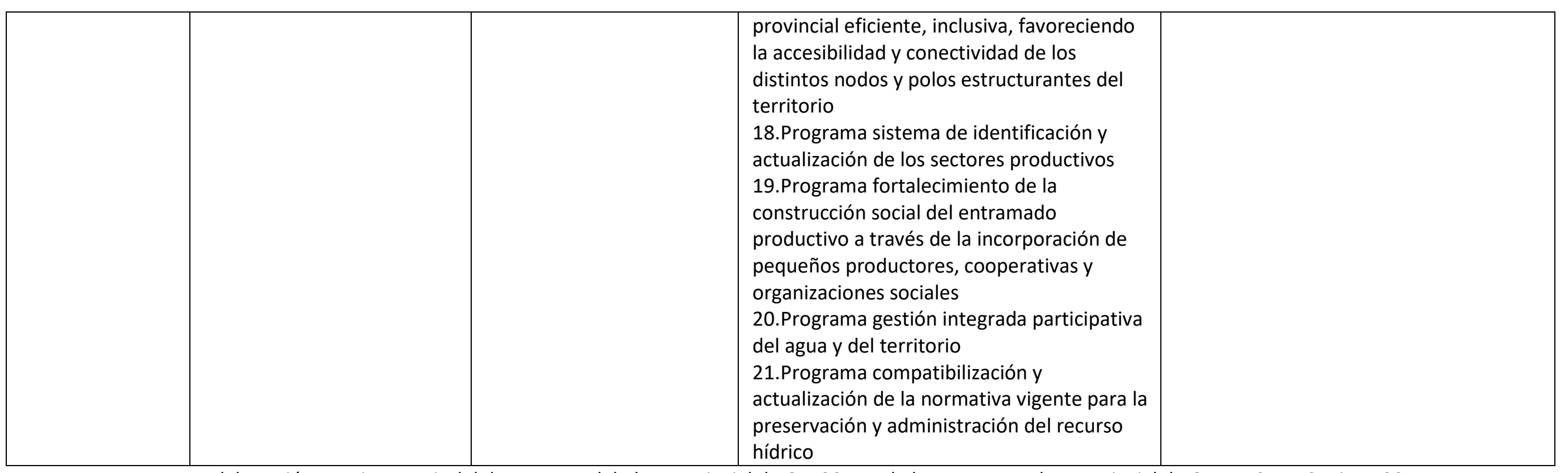

Fuente: elaboración propia a partir del documento del Plan Provincial de OT, 2014 y de la propuesta Plan Provincial de OT. UNCuyo-Conicet, 2014. 